\title{
Ray of hope for sub-Saharan Africa's paratransit: Solar charging of urban electric minibus taxis in South Africa
}

\author{
C.J. Abraham ${ }^{\text {a }}$, A.J. Rix ${ }^{\text {a }}$, I. Ndibatya ${ }^{\text {a,b }}$, M.J. Booysen ${ }^{\text {a,* }}$ \\ a Department of EEE Engineering, Stellenbosch University, South Africa \\ b College of Computing and Information Sciences, Makerere University, Uganda
}

\section{A R T I C L E I N F O}

\section{Article history:}

Received 12 June 2021

Revised 20 August 2021

Accepted 27 August 2021

Available online $\mathrm{xxxx}$

\section{Keywords:}

Electric vehicle

Paratransit

Minibus taxi

Demand management

Renewable energy

\begin{abstract}
A B S T R A C T
Minibus taxi public transport is a seemingly chaotic phenomenon in the developing cities of the Global South with unique mobility and operational characteristics. Eventually this ubiquitous fleet of minibus taxis is expected to transition to electric vehicles, which will result in an additional energy burden on Africa's already fragile electrical grids. This paper examines the electrical energy demands of this possible evolution, and presents a generic simulation environment to assess the grid impact and charging opportunities. We used GPS tracking and spatiotemporal data to assess the energy requirements of nine electric minibus taxis as well as the informal and formal stops at which the taxis can recharge. Given the region's abundant sunshine, we modelled a grid-connected solar photovoltaic charging system to determine how effectively PV may be used to offset the additional burden on the electrical grid. The mean energy demand of the taxis was $213 \mathrm{kWh} / \mathrm{d}$, resulting in an average efficiency of $0.93 \mathrm{kWh} / \mathrm{km}$. The stopping time across taxis, a proxy for charging opportunity, ranged from $7.7 \mathrm{~h} / \mathrm{d}$ to $10.6 \mathrm{~h} /$ $\mathrm{d}$. The energy supplied per surface area of PV to offset the charging load of a taxi while stopping, ranged from 0.38 to $0.90 \mathrm{kWh} / \mathrm{m}^{2}$ per day. Our simulator, which is publicly available, and the results will allow traffic planners and grid operators to assess and plan for looming electric vehicle roll-outs.

(c) 2021 The Author(s). Published by Elsevier Inc. on behalf of International Energy Initiative. This is an open access article under the CC BY-NC-ND license (http://creativecommons.org/licenses/by-nc-nd/4.0/).
\end{abstract}

\section{Introduction}

Paratransit in Africa's developing countries differs substantially from that of developed countries, from its inception to its vehicle types to its operations. In developed countries, paratransit usually means a pointto-point flexible demand-responsive transport service customised with special requirements for the elderly and the disabled (Askari et al., 2021; Behrens et al., 2017). For Africa's developing countries, paratransit means an organically evolved, informal, market-oriented, self-organising urban transport service that operates somewhere between private passenger transport and conventional public transport in terms of cost, scheduling, routes and quality of service (Ndibatya \& Booysen, 2021; Neumann \& Joubert, 2016). Here the paratransit system consists of shared-ride, demand-responsive privately owned vehicles, such as the minibus taxis in Lagos, Johannesburg, Nairobi and Kampala, or the single-passenger motorcycle taxis ("boda bodas") in Kampala, or the tricycle taxis ("tuk-tuks") in Nairobi (Booysen et al., 2013; Diaz Olvera et al., 2019; Mutiso \& Behrens, 2011).

Paratransit plays a vital role as the primary form of transport in subSaharan Africa's public transit system. It transports more than $70 \%$ of the daily commuters and is a source of livelihood for many families (Behrens

\footnotetext{
* Corresponding author.

E-mail address: mjbooysen@sun.ac.za (M.J. Booysen).
}

et al., 2015). Paratransit in the region takes various forms, such as minibus taxis, motorcycle taxis and bicycle taxis (Ehebrecht et al., 2018), with minibus taxis carrying the largest daily share of passengers (Behrens et al., 2017). Powered by internal combustion engines, the taxis contribute to the emission of greenhouse gases and a general decline of air quality in African cities (Collett \& Hirmer, 2021; Odhiambo et al., 2021).

Travel by paratransit accounts for approximately $70 \%, 90 \%, 91 \%$, and 98\% of the road-based public trips in Johannesburg, Lagos, Kampala and Dar es Salaam, respectively (Behrens et al., 2015; Evans et al., 2018). Of these paratransit passenger trips, $83 \%$ are by minibus taxi (Dorothy et al., 2016; Evans et al., 2018; KCCA, 2016).

\section{The revolution in sub-Saharan Africa's paratransit}

In sub-Saharan Africa, the public transport industry experienced two fundamental organic changes in the last quarter of the nineteenth century. The first was the shift of transport services proprietorship, from public to private, most often sole proprietorship, as a result of the World Bank's structural adjustment policies of the 1990s that restricted financing to state-owned entities, leading to their eventual collapse (Kumar, 2011; Ajay Mahaputra Kumar et al., 2008; Cervero \& Golub, 2007). The second was the gradual introduction of low-capacity (fiveto twenty-seater) passenger-carrying vehicles to fill the public transport vacuum (Behrens et al., 2015; Diaz Olvera et al., 2019; Jennings \& 
Behrens, 2017; Mutiso \& Behrens, 2011). From the five seater Anglia (Ford cars of the 1970s), to the 10-seater Peugeot 204 (1980s), to the current 16-seater Toyota HiAce, paratransit service vehicles have been of many types in many countries. Since the 1990s, the fourth and fifth generations (H100 1989-model and H200 2004-model) of the Japanese Toyota HiAce have dominated the paratransit market in Africa. The Toyota HiAce trades under several names depending on the country of assembly, such as Toyota Quantum in South Africa and Toyota Ventury in Thailand. Originating simply as a complementary transport service, the minibus taxis have become a way of life for the urban poor in several African cities.

Two competing views have broadly shaped discourse on the minibus taxis as part of the paratransit system in Africa. The predominant view is that minibus taxis and paratransit in general are the most extreme example of public transport failure in the developing world (Lucas et al., 2019). To support this view, terms such as "chaotic", "unsustainable", "unsafe" and "pollutants" are common in the literature in reference to the minibus taxis (Agbiboa, 2016; Pojani \& Stead, 2017, 2018; Venter et al., 2019). In fact, the contribution of minibus taxis to urban air pollution is significant, partly because they are old (often older than 20 years) and they stand idling their engines for long hours, thus hugely contributing to greenhouse gas emissions and the deteriorating air quality in African cities. The World Health Organisation classifies exposure to ambient air pollution (AAP) as a major threat to human health in sub-Saharan Africa, linking it to the increase in cardiovascular and cardiopulmonary diseases and lung cancer and respiratory infections (Amegah \& Agyei-Mensah, 2017; Dalal et al., 2011). Consequently, proponents of this view advocate for a total overhaul of the minibus taxi industry and its replacement with the western idea of orderly transport, the bus rapid transit (BRT) system.

Proponents of the second view advocate for a hybrid future, with paratransit complementary to the scheduled BRT. However, the adoption of this view is very slow and facing much resistance from the paratransit operators. Although several benefits would accrue to them (such as job security for the drivers, proper regulation, and government subsidies) they would lose their autonomy and the elements of selforganisation that formed the core of the original paratransit in Africa.

An alternative third view is emerging, which imagines Africa's paratransit system as a complex adaptive system, composed of many interdependent components that interact non-linearly, often operating between "chaotic" and semi-orderly states (Behrens et al., 2015; Goodfellow, 2017). This view acknowledges the coping mechanisms and innovative forms of self-organisation exhibited by paratransit and how the system adapts to serve the population's mobility needs with little or no centralised control. Actually paratransit "chaos" reveals to some degree the hidden order described by Hecht as the "invisible governance ... that maintains competing agendas and aspirations in some kind of functional and parallel existence" (Hecht, 2007).

The minibus taxi paratransit came into being to suit the mobile lifestyle of the urban poor in sub-Saharan Africa. It is unlikely that the minibus taxis will be phased out of Africa's cities any time soon. They are ubiquitous and will continue for many reasons: their schedule flexibility, the urban sprawl, the irregular commuter movement patterns in urban spaces due to informal employment and the socio-cultural lifestyles of the urban poor in developing cities. However, the environmental cost of running these old internal combustion engine vehicles is worrying. It has triggered discussions about the possibility of transitioning to electric minibus taxis as part of the global electrification and sustainability agenda (Collett \& Hirmer, 2021).

\section{The transition to electric vehicles and the electric minibus taxi}

The development of low-carbon transport in cities is crucial to the global agenda to combat climate change's various effects sustainably. In fact, three of the seventeen United Nations Sustainable Development
Goals, one, eleven and thirteen, are clean energy, sustainable cities and climate action (Zinkernagel et al., 2018).

The Intergovernmental Panel on Climate Change (IPCC) estimates that the transport sector generates $23 \%$ of the global energy-related greenhouse emissions (Sims et al., 2014). In sub-Saharan Africa the deteriorating air quality resulting from ambient air pollution and a high concentration of particulate matter $\left(\mathrm{PM}_{2.5}\right)$ is partly attributed to vehicle emissions (Lozano Gracia et al., 2021; Rajé et al., 2018; Singh et al., 2020). The WHO estimated that $1,100,000$ deaths in Africa in 2016 were due to air pollution, though the figure may be higher than reported because air pollution epidemiological data is limited (United Nations, Department of Economic and Social Affairs, Population Division, 2019; World Health Organization et al., 2018). Akumu estimates the cost of air pollution in African cities to be as high as $2.7 \%$ of GDP (Akumu, 2014).

Consequently, electrification is promoted as a low-carbon transport strategy to reduce combustion emissions and slow down the possibly damaging effects of climate change. In the same spirit, the transition to electric vehicles is gradually picking up in developing countries to the extent that some vehicle manufacturers are planning to phase out internal combustion engines. Sub-Saharan Africa is seeing a few isolated pilot electric vehicle projects, mainly focusing on micro-mobility (as motorcycles and tricycles), as well as buses and private cars (Black et al., 2018). At present, there is no known electric vehicle transition initiative targeting the paratransit industry, let alone the minibus taxis that are responsible for more than $80 \%$ of the public transport trips in the region.

This paper builds a foundation for evaluating the eventual impact of the transition to electric minibus taxis on cities' electrical grids, localised pollution, carbon footprint and taxi owners' profitability. Specific attention is given to the energy requirements of these vehicles, the potential distribution of charging stations and the potential electricity generation capacity from renewable sources.

\section{Overview of earlier studies and approaches}

Initiatives to achieve sustainable urban mobility often follow a three-pronged transport decarbonisation approach, the "Avoid-ShiftImprove" paradigm (Galuszka et al., 2021; Lah, 2017). This approach aims to reduce trips, shift towards public transport and non-motorised modes and improve vehicle efficiency coupled with electrification (Le \& Trinh, 2016; Osei et al., 2021). In sub-Saharan Africa, the avoid and shift approaches have not been intensively studied (Krüger et al., 2021). The focus has been primarily on improvements: urban traffic management strategies such as widening roads, optimising road signalling and encouraging multi-modal transport (developing mass transit systems such as BRT and promoting walking and cycling) (Krüger et al., 2021; Shams \& Zlatkovic, 2020; Sietchiping et al., 2012; Venter et al., 2018). Ironically, evidence from other world cities suggests that building freeways and roads around cities only increases car dependence and thus intensifies congestion and pollution (Sietchiping et al., 2012). 11:introduction_shifting_to_evs Shifting to electric vehicles in public transport and paratransit is an approach that has been neglected. The literature on paratransit in sub-Saharan Africa focuses on aspects of sector governance (Goodfellow, 2017) and regulation and reforms (Jennings \& Behrens, 2017; Lucas et al., 2019), but seldom on operations (Ndibatya \& Booysen, 2020), mobility characteristics (Ndibatya \& Booysen, 2021) and the prospects of electric mobility integration (Galuszka et al., 2021).

Research from outside the region shows that electric vehicles are three times more efficient than internal combustion engine vehicles and twice as efficient as hybrid vehicles (Du et al., 2017; Weiss et al., 2020). This efficiency is achieved partly by the efficient braking systems and elimination of idling losses and the consequent saving of energy for the vehicle's actual movement (Weiss et al., 2020). Although debate continues on the economic and environmental trade-offs associated 
with electric vehicles (Li et al., 2016), there is evidence of sustainable electric vehicle deployment. Some researchers argue that deploying electric vehicles shifts gasoline usage to coal-fired power generation, which exacerbates $\mathrm{CO}_{2}$ emissions by the power systems (Li et al., 2016). However, electric vehicle proponents counter-argue that, on a macro-scale, these vehicles' impact in terms of $\mathrm{CO}_{2}$ emissions depends mainly on the charging strategy and that the emissions can be reduced by optimising the use of renewable energy sources such as solar power (Buresh et al., 2020; Schücking et al., 2017). In one of the scarce and isolated publications on electric vehicles in sub-Saharan Africa, Buresh et al. (2020) note that South Africa (like many countries in the region) has high levels of insolation (the measure of solar energy at a place over a specified time), from between 4.5 and $6.5 \mathrm{kWh} / \mathrm{m}^{2}$ per day, with annual sunshine averaging more than $2500 \mathrm{~h}$. This implies that the region has an excellent chance of harnessing this renewable energy source to power electric vehicles. Indeed, projects researching alternative renewable energy have taken shape in the region (Jadhav et al., 2017), though not targeting electric vehicles for public transport services.

Two main research gaps remain in the literature on sub-Saharan Africa's transition to electric minibus taxis. One is the mobility characteristics of minibus taxis. As Quirós-Tortós et al. (2018) observe, to estimate the charging requirements and vehicle performance of an electric vehicle we need to know its mobility patterns, such as distance, travelling time and idle time (or stopping time and duration). In other words, the vehicle's mobility has spatio-temporal dimensions. Apart from the findings of isolated studies on minibus taxi mobility, such as those by Ndibatya and Booysen (2021), the general mobility dynamics of paratransit in sub-Saharan Africa are unknown. The other is the region's potential for renewable energy from different sources such as solar PV, wind and bio-fuel as part of this transition (Jadhav et al., 2017; Sawadogo et al., 2020; Soares et al., 2019).

From the sparseness of the work, it is clear that we lack information on the mobility of minibus taxis in sub-Saharan Africa and specifically the requirements of these minibus taxi fleets if they are converted to electric vehicles (Collett \& Hirmer, 2021; Odhiambo et al., 2021; Booysen et al., 2021). Our reproducible method for determining their mobility and analysing the generated data will fill the gap and help city planners as well as fleet owners to improve their future operations.

\section{Contribution}

First the paper explores for the first time the energy requirements of electric minibus taxis in an urban paratransit system, on journeys within and between towns and cities. This was done by using an electric vehicle model and a year's worth of GPS tracking data ll:introduction_fcd_def (time-stamped geographical-coordinates recorded at minutely intervals) in a micro traffic simulator. Second the paper explores the potential charging opportunities at the multitude of formal and organicallyformed informal stops locations. To do this, we analyse the GPS data to determine the locations of these stops, as well as the wildly variable arrival times and stop durations. Third we use these mobility results (movement patterns, stop locations and stop durations) in a solar PV simulator to also establish the potential for charging with grid-connected solar PV, without battery storage, at these stops. Our method is limited to a case study in an urban scenario near Cape Town in South Africa, but our fourth contribution is our integration and stop extraction software under the GPLv3 license, which can be modified and used to perform similar evaluations. Finally, we assess the impact on the struggling South African grid of converting all the minibus taxis in South Africa to electric vehicles, with and without solar augmentation.

\section{Method}

This section describes the dataset and the three models used for the research: the minibus taxi (MBT) mobility model, the photovoltaic (PV) model and the electric minibus taxi (eMBT) electric vehicle (EV) model.
It describes the pre-experimental collection and analysis of the floating car data from a fleet of nine internal combustion engine minibus taxis. Inter-town MBT mobility modelling involved spatial clustering of floating car data to identify stopping events and generate routes between stops in preparation for PV and eMBT modelling. We present two model simulation setups for the EV and PV models and discuss their application to our urban paratransit context. The PV model was based on the System Advisor Model (SAM) developed by the National Renewable Energy Laboratory (Blair et al., 2014). We ran the PV and the EV models independently in a micro-transport simulator (SUMO) (Kurczveil et al., 2014; Lopez et al., 2018), then recorded and analysed the eMBT energy and PV requirements for each simulated context.

A custom simulation software was written in Python to automate the steps in this methodology. The software is publicly available at: https://gitlab.com/eputs/embt-sim/

\section{Mobility}

The dataset consisted of floating car data obtained by tracking urban minibus taxis operating on bidirectional routes connecting Stellenbosch, Brackenfell and Somerset West in the Western Cape Province of South Africa. The area under study is defined by coordinates are $(34.229224,18.656884)$ and $(-33.786222,18.969438)$ as shown in Fig. 1a. The data obtained from Mix Telematics (a local fleet management service provider), consisted of timestamped geo-locations (latitude and longitude), speed and direction, logged at a frequency of one minute from onboard tracking devices for over two years. After cleaning, filtering and performing pre-data loading preparations, we had an average of 201 days' worth of floating car data per minibus taxi for use in EV and PV modelling.

\section{Spatial clustering and analysis}

An overlay heatmap showing the intensity variation of minibus taxi activity (based on the count of GPS data points) was plotted as shown in Fig. 1a. Three high-intensity areas were visible in the heatmap: Stellenbosch, Brackenfell (west of Stellenbosch) and Somerset West (south of Stellenbosch). We interpreted these three areas as the epicentres of minibus taxi activity, a view that closely matches that of Ebot Eno Akpa et al. (2016).

We used the density-based spatial clustering of applications with noise (DBSCAN) algorithm to group high-density closely related data points (or geo-locations), forming spatial clusters of data points that represented significant events (such as stopping and movement) during normal minibus taxi operations. We chose the DBSCAN algorithm because of its robustness to outlier detection, its ability to discover clusters with uneven densities and arbitrary shapes, and the fact that it does not need prior knowledge of the number of clusters (Liu et al., 2012; Renjith et al., 2020). For cluster analysis we used a Python implementation of the DBSCAN algorithm from the Scikit-Learn package (Pedregosa et al., 2011). The minimum cluster size (min_samples) was 70, and the maximum distance between neighbouring points in a cluster (max_eps) was $0.0002^{\circ}$ (Ndibatya et al., 2014). Fig. 1b shows the spatial distribution of cluster centroids overlaid on OpenStreetMap.

\section{Identifying minibus taxi stops}

To generate the mobility patterns and establish the potential for charging at stops, it was necessary to identify the spatial clusters with stopping events. Additional temporal analysis was required to determine the stop times and stop durations. We therefore further analysed each spatial cluster to identify sets of data points representing either a stop event or a movement event within the cluster's spatial extent. A stop event in our work is closely related to a "stay point" as defined by Zheng et al. (2009) and Damiani et al. (2014) and refers to a series of consecutive GPS locations within a cluster's spatial extent, with a taxi velocity below a threshold of $1 \mathrm{~km} / \mathrm{h}$. The arrival time of the stop event is the time of the first GPS location in the series, and the duration 


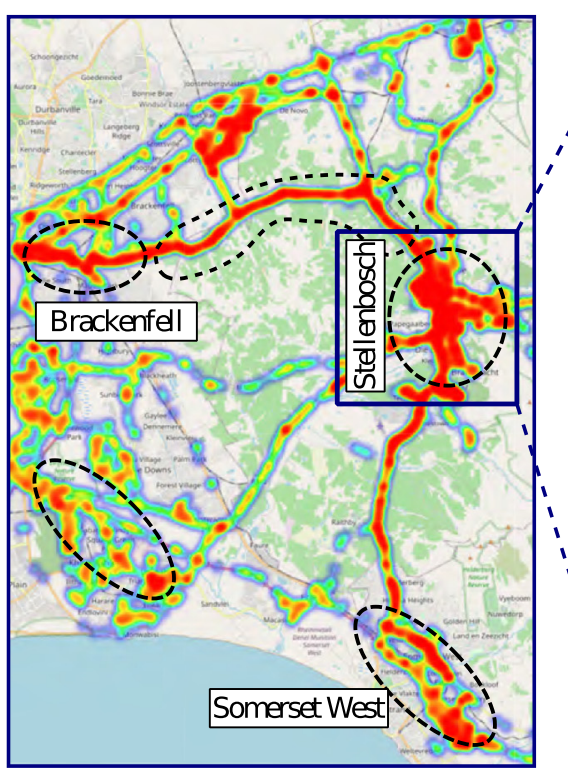

(a)

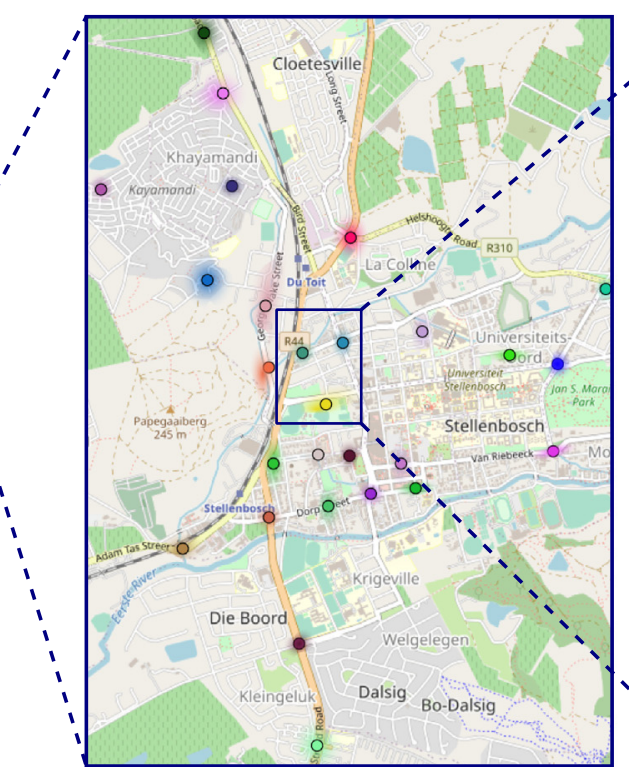

(b)

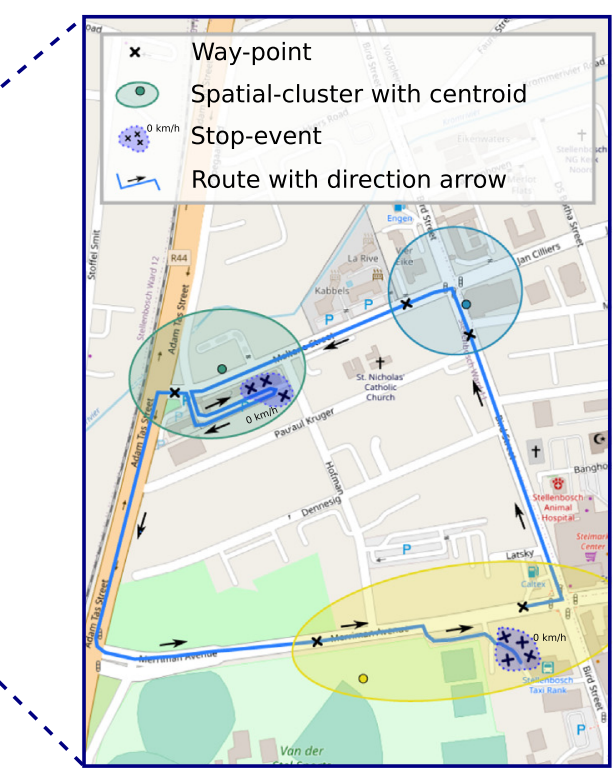

(c)

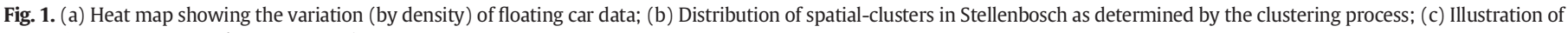
way points, stop events and route generation process.

of the stop-event is the difference between the timestamps of the first and last GPS locations in the series as illustrated in Fig. 1c. The movement events (or waypoints) represented by all the cluster data points that do not belong to the 'stop event' category were preserved for use during minibus taxi route generation in the EV model.

For each spatio-temporal cluster we generated a statistical summary describing the total number of stop events, average stop arrival time, average stop duration, and the standard deviations from these. The statistical summary helped to identify the spatial clusters with the most stop events and their typical time and duration. We were thus able to identify spatial clusters with many stop events as formal taxi stops (terminuses). Spatial clusters with lower counts could be identified as intersections where the taxis pause for traffic, or informal stops made en route to pick up passengers. Clustering the stop events temporally also helped to identify the times when these stops typically occurred.

\section{Generating routes}

To simulate the mobility of MBTs between the three towns and subsequently study their energy requirements, we generated the routes linking the identified stops. A route in this context is a series of edges connecting two or more stop events, often starting and ending in different clusters (or cluster centroids). A simulated MBT follows pre-selected routes as part of its daily route plan within the simulation boundary.

We used the stop events' cluster centroids, the waypoints (GPS data representing moving events), the roads network, and SUMO's shortest path Djikstra algorithm to generate the routes. The underlying road network was based on OpenStreetMaps (OSM) (OpenStreetMap contributors, 2017), which included the roads, intersections, speed limits, and traffic lights information. All the GPS data points (including cluster centroids and waypoints) were snapped to the OpenStreetMap's road network, and the shortest path between the origin and destination points of interest was computed using SUMO's implementation of the Djikstra algorithm (Lopez et al., 2018). This algorithm searches for the route with the least cost (Lewis, 2020), where the cost can be the distance, time, or electricity consumption of the simulated EV. In this study, we defined the cost as the distance (we omitted the other options due to simulation performance considerations). For each simulated day we generated a route, and from these routes we computed extra information that affects an EV's (or eMBT's) energy usage, such as the total distance, the road inclination and the road curvature.

\section{The eMBT EV model}

We set up a simulation model using a custom SUMO electric vehicle simulation model, SUMO EV, to measure the temporal variation of power and energy usage and the relationships between power consumption and eMBT speed. The model's parameters were specified to match the prevailing MBT used in South Africa, the Toyota Quantum. The weight and front surface area used for a synthetic eMBT were measured from one of the Toyota Quantum minibus taxis operating in Stellenbosch. We approximated the rest of the parameters according to the recommendations by Fridlund and Wilen (2020). These parameters include: height $2.3 \mathrm{~m}$, width $1.9 \mathrm{~m}$, front-facing surface area $4 \mathrm{~m}^{2}$, weight $2900 \mathrm{~kg}$, constant power intake $100 \mathrm{~W}$, propulsion efficiency 0.8 , recuperation efficiency 0.5 , roll drag coefficient 0.01 and radial drag coefficient 0.5 . The simulation program initialised the eMBT model for each date that was simulated. The eMBT model was applied to the generated routes. For every second of simulation time, the simulator logged the energy consumption and speed of the eMBT as it progressed along its route.

With an average of 201 routes per taxi, the volume of output data from the model was huge. Our goal was to obtain useful metrics that would summarise this data. The first metric we considered was the average power usage profile of the fleet of nine eMBTs. Such a profile would indicate how much power the eMBTs used at various points in time. This profile would be indispensable, for example, for testing the hypothesis that there would be a good charging opportunity at midday. It would also show what order of magnitude the motor size should be. We calculated the profile by obtaining the power-vs-time profile for each day, averaging this across all days for each eMBT, and then averaging that across all eMBTs in the fleet. The profile was plotted with respect to time.

\section{PV model simulation setup}

We set up the SAM-based PV model to calculate the energy available from photovoltaic sources and to study the daily charging potential for 
each eMBT in a synthetic fleet of nine eMBTs. The model generates the plane-of-array solar irradiance profile based on radiometric data, solar azimuth angle, and photovoltaic panel tilt angle. We used radiometric data for a year sampled every 15 min from the National Solar Radiation Database (Sengupta et al., 2018). The azimuth and tilt angles were set at $0^{\circ}$ (North) and $20^{\circ}$, respectively, a common configuration which maximises energy yield in South Africa (Le Roux, 2016).

To get the output power profile of the PV array, a 16\% system efficiency was applied to the irradiance profile, i.e., $20 \%$ and $80 \%$ were used for the solar panel and balance of the system (including the inverter), respectively. We used the stop event analysis done earlier to further analyse the battery charging potential from solar PV by evaluating the times at which the stop events occurred and their durations. We first applied thresholds to filter out stop events with durations above $8 \mathrm{~h}$ or below $20 \mathrm{~min}$. This was to ensure that stop events irrelevant to our study did not skew the statistics. Stops above $8 \mathrm{~h}$ would only occur on special events such as a public holiday or a vehicle breakdown. Stops under 20 min would be too short for charging. These stop events were grouped according to the spatial cluster in which they occurred, and temporal clustering was done within each spatial cluster to obtain spatio-temporal clusters.

Based on the stop events detected during the spatio-temporal clustering, we computed the potential energy sourced from PV per day. For each eMBT stop event, the PV output-power-profile was integrated from the beginning to the end of the stop event in order to calculate the total energy that could be charged from PV during that stop event. The (i) T1001: North Terminus (C111)

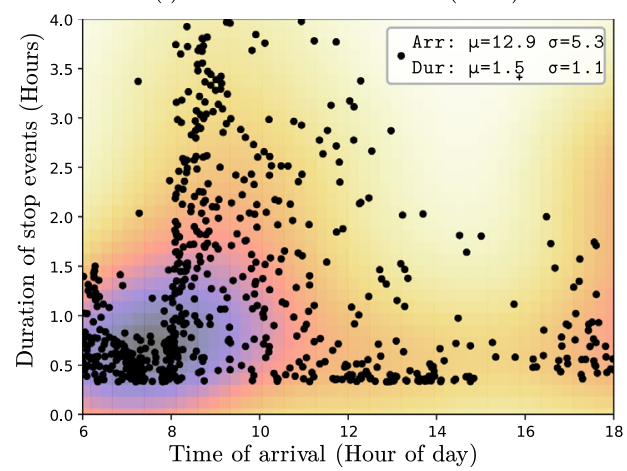

Time of arrival (Hour of day)

(i) T3001: North Terminus (C311)

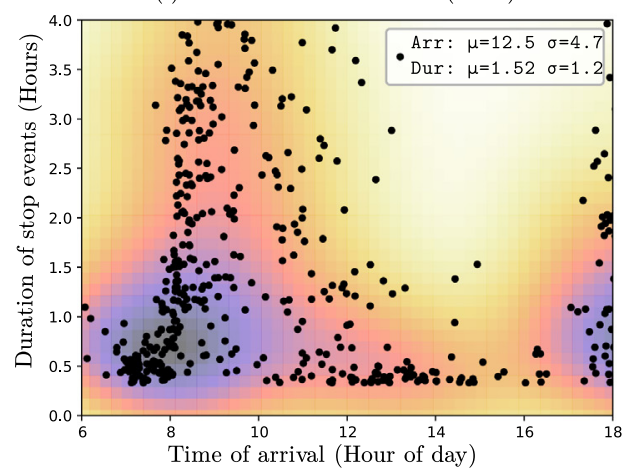

(i) T5000: North Terminus (C501)

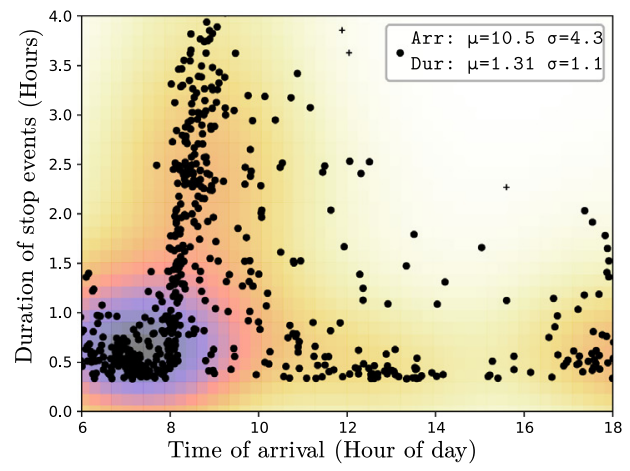

(ii) T1001, South Terminus (C113 \& C114)

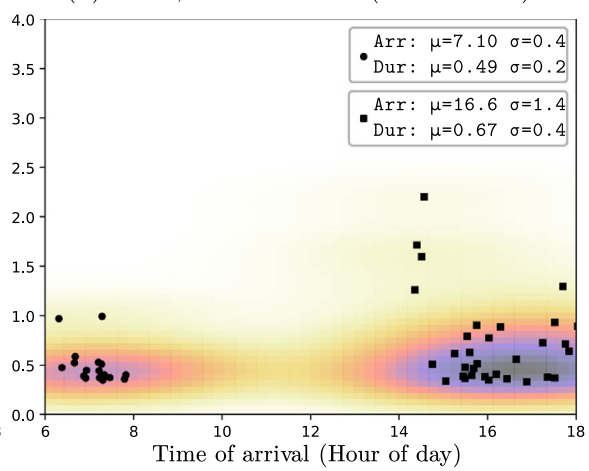

(a) (iii) T1001, Central Terminus (C112)

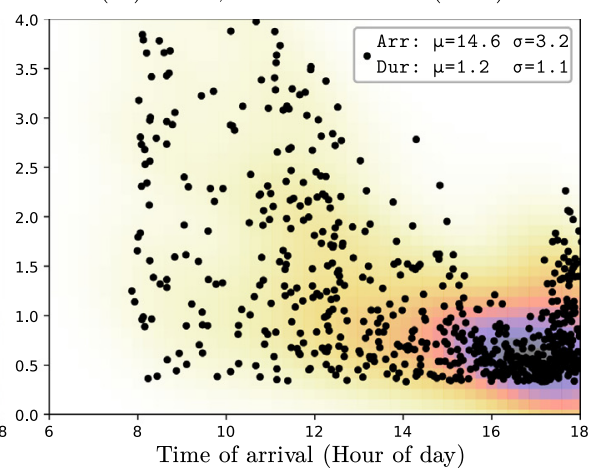

(ii) T3001: South Terminus (C313 \& C314)

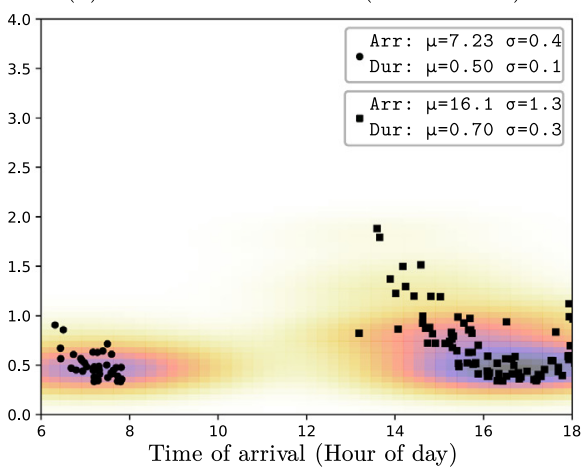

(iii) T3001: Central Terminus (C312)

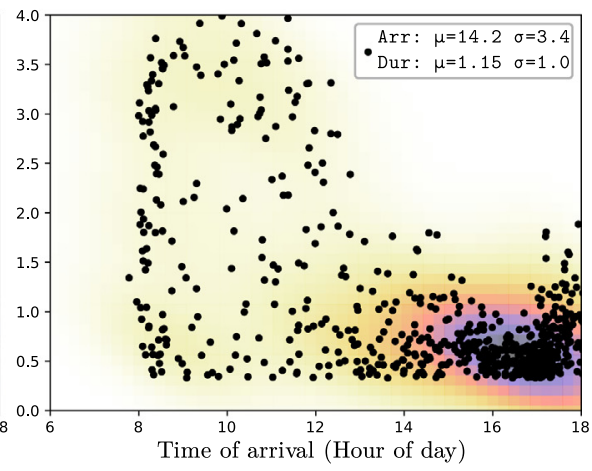

(b)

(ii) T5000, South Terminus (C503 \& C504)

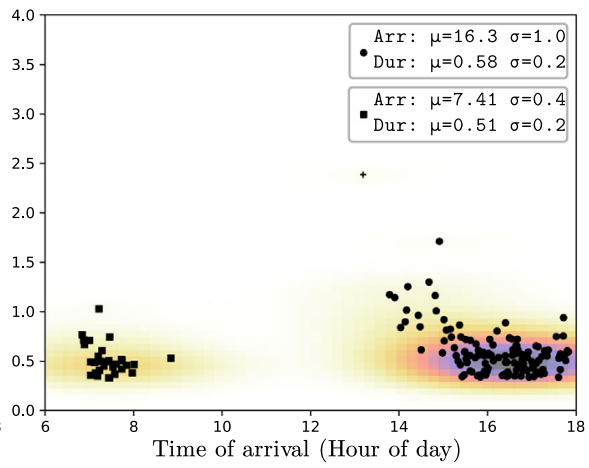

(iii) T5000: Central Terminus (C502)

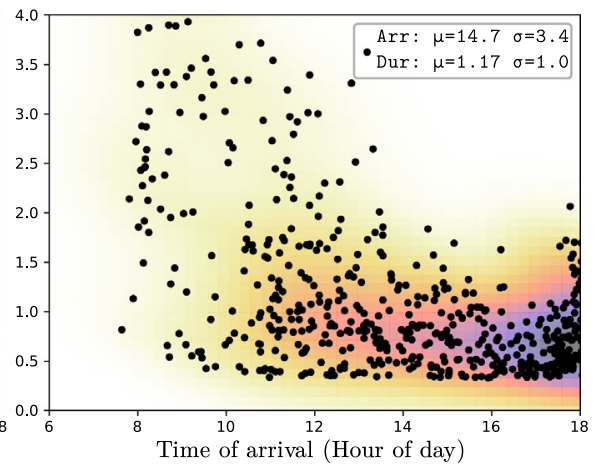

(c)

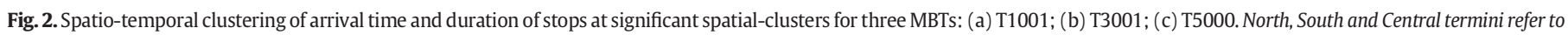
the spatial-clusters situated near termini found in Kayamandi in Stellenbosch, Somerset West, and Stellenbosch Central, respectively. 
PV energy of each stop event was summed to get the total energy that could be charged from PV for that day as a function of the area of the PV array. These "daily PV charging potentials" were aggregated for each taxi and plotted as box plots. This metric allowed us to approximate the size of the PV array required to provide a certain percentage of an eMBT's energy demands.

\section{Results and discussion}

This section describes the results obtained from applying our three models to the floating car data from Stellenbosch and its surrounds. The results obtained refer specifically to the MBT mobility, the eMBT's power requirements and the potential charging opportunities. The charging opportunities are separated into stop times for the purpose of source-ambivalent charging, and potential charging from PV.

The inter-town MBT mobility modelling provides spatial clustering of the identified stop events that serve as input to the PV modelling while generating routes used to determine the power requirements of the individual eMBT and the fleet of eMBTs.

\section{Mobility analysis}

Fig. 2 shows the results of the spatio-temporal clustering of data from three minibus taxis to determine the stops. Despite the seemingly chaotic patterns, the clustering analysis identified spatio-temporal clusters of stops. The figure shows how each minibus taxi has a vertically distributed (i.e. varying duration) morning cluster at around 8:00 am, and a horizontally distributed (i.e. varying arrival time) cluster in the evening. For example, the spatio-temporal clusters in the South Terminus indicate that those spatial clusters were visited in the morning and in the evening.

The spatio-temporal clusters were primarily used in SUMO to generate the traffic simulator's mobility patterns and then analyse the charging potential during stationary periods. A statistical summary of all the identified stop clusters, showing the stationary periods during daylight hours grouped by taxi, is provided in Table 1 . Although the standard deviation is substantial, the mean stop durations of the clusters were more than one hour for at least two stops per taxi. The arrival times of the longer stops were all between 10:30 am and 3:00 pm except for one outlier taxi T6000, which exhibited wildly different clustering results. Accordingly, the clusters indicate that there should be substantial potential for charging from solar power.

\section{Energy analysis}

The output of the EV simulation is shown in Fig. 3. The mean instantaneous power demand versus time of a working weekday is shown in Fig. 3a. A clear typical temporal profile is apparent for the minibus taxis, closely matching the peak traffic hours. There is a sharp peak demand period from 6:00 am to 9:00 am, with a peak value of $32 \mathrm{~kW}$. A diminished demand with a mean of $6 \mathrm{~kW}$ is observed from 9:00 am to 1:00 $\mathrm{pm}$, constituting a period of substantially reduced activity, due to the taxis being stationary during this time. This demonstrates the potential for charging, particularly with solar energy, due to the high insolation at midday. This is followed by a gradual increase to a less pronounced peak value of $30 \mathrm{~kW}$ between 5:00 pm and 6:00 pm. This flatter evening demand profile slowly declines to return to the trough of $7 \mathrm{~kW}$ by 9:00 pm. Complete inactivity is observed from $11: 30 \mathrm{pm}$ to $4: 30 \mathrm{am}$. Not only is this profile clearly defined, but the variation between taxis, shown by the minimum and maximum profiles in the shaded area, is minimal. The only substantial deviation is the increase in the maximum profile just after 9:00 pm, which results from the long-distance journeys over weekends (departing at 9:00 pm on Friday evenings) and holidays, as reported by Ebot Eno Akpa et al. (2016).

This profile indicates the energy demand profile requirements of the eMBTs, and already hints at substantial charging potential during the evening - probably from grid power - and during the middle of the day - preferably from solar power.

Fig. 3b shows the MBT's speed versus time of the day, the similarity of which highlights the substantial impact of speed on power draw. The energy required and the distance travelled was found by integrating the the power and speed profiles with respect to time. It was found that the energy required was close to linearly proportional to the distance travelled, which demonstrates that a simpler distance-based model would have provided good estimations and required substantially less processing power. The mean energy required per day is $213 \mathrm{kWh}$.

The distribution of energy usage per taxi per day, is shown in Fig. 4a for the nine taxis. The taxis' energy usage is similar, with the median energy per taxi per day across all taxis ranging from $189 \mathrm{kWh}$ to $252 \mathrm{kWh}$, with the mean of the medians equal to $215 \mathrm{kWh}$. For any given taxi, on $75 \%$ of the days, less than $303 \mathrm{kWh}$ is used. Eight of the nine taxis, on all days, use less than $420 \mathrm{kWh}$, while the other taxi uses up to $490 \mathrm{kWh}$.

The results show that the maximum daily impact that a taxi would have on the grid is approximately $500 \mathrm{kWh}$. For $75 \%$ of the time, the impact would be less than $300 \mathrm{kWh}$. This impact can be reduced by using solar energy to meet part of the energy requirements. Finally, it can be noted that the actual battery size of the taxi could be considerably lower than the daily energy usage, since the taxi can be charged during the day at its longer stops.

\section{Charging potential}

A sizable eMBT fleet could place a substantial burden on the local electrical distribution network and power generation capacity of countries in sub-Saharan Africa. The strain on the local network could cause infrastructure and electrical supply problems, so we investigated the

Table 1

Summary of the MBT stop events identified during the cluster analysis. The clusters are grouped by vehicle ID and sorted by duration in descending order. The vehicles with boldfaced IDs were plotted in Fig. 2. (Note: $\mu=$ Mean, $\sigma=$ Standard deviation).

\begin{tabular}{|c|c|c|c|c|c|c|c|}
\hline \multirow{2}{*}{$\begin{array}{l}\text { Minibus } \\
\text { Taxi ID }\end{array}$} & \multirow{2}{*}{$\begin{array}{l}\text { Spatio-temporal } \\
\text { Cluster ID }\end{array}$} & \multirow{2}{*}{$\begin{array}{l}\text { Stop events } \\
\text { count }\end{array}$} & \multicolumn{2}{|c|}{$\begin{array}{l}\text { Arrival } \\
\text { (h) }\end{array}$} & \multicolumn{2}{|c|}{$\begin{array}{l}\text { Duration } \\
\text { (h) }\end{array}$} & \multirow{2}{*}{$\begin{array}{l}\text { Terminus } \\
\text { Name }\end{array}$} \\
\hline & & & $\mu$ & $\sigma$ & $\mu$ & $\sigma$ & \\
\hline \multirow[t]{4}{*}{ T1000 } & C101 & 302 & 12.0 & 4.8 & 1.5 & 1.2 & North \\
\hline & C102 & 309 & 14.1 & 3.1 & 1.4 & 1.2 & Central \\
\hline & C104 & 15 & 17.4 & 1.3 & 0.7 & 0.3 & South \\
\hline & C103 & 18 & 7.1 & 0.4 & 0.5 & 0.2 & South \\
\hline \multirow[t]{4}{*}{ T1001 } & $\mathrm{C} 111$ & 1074 & 12.9 & 5.3 & 1.5 & 1.1 & North \\
\hline & C112 & 782 & 14.6 & 3.2 & 1.2 & 1.1 & Central \\
\hline & C114 & 41 & 16.6 & 1.4 & 0.7 & 0.4 & South \\
\hline & $\mathrm{C} 113$ & 17 & 7.1 & 0.4 & 0.5 & 0.2 & South \\
\hline \multirow[t]{4}{*}{ T3001 } & C311 & 686 & 12.5 & 4.7 & 1.5 & 1.2 & North \\
\hline & C312 & 689 & 14.2 & 3.4 & 1.2 & 1.0 & Central \\
\hline & C314 & 87 & 16.1 & 1.3 & 0.7 & 0.3 & South \\
\hline & C313 & 37 & 7.2 & 0.4 & 0.5 & 0.1 & South \\
\hline \multirow[t]{4}{*}{ T4000 } & C402 & 495 & 14.2 & 3.4 & 1.5 & 1.4 & Central \\
\hline & C401 & 406 & 11.8 & 4.5 & 1.3 & 1.0 & North \\
\hline & C404 & 42 & 16.4 & 1.0 & 0.6 & 0.2 & South \\
\hline & C403 & 29 & 7.0 & 0.4 & 0.5 & 0.1 & South \\
\hline \multirow[t]{4}{*}{ T5000 } & C501 & 787 & 10.5 & 4.3 & 1.3 & 1.1 & North \\
\hline & C502 & 709 & 14.7 & 3.4 & 1.2 & 1.0 & Central \\
\hline & C503 & 139 & 16.3 & 1.0 & 0.6 & 0.2 & South \\
\hline & C504 & 30 & 7.4 & 0.4 & 0.5 & 0.2 & South \\
\hline \multirow[t]{3}{*}{ T6000 } & C601 & 34 & 8.5 & 0.4 & 5.9 & 1.0 & North \\
\hline & C602 & 82 & 16.6 & 1.1 & 1.1 & 0.8 & North \\
\hline & C603 & 52 & 7.1 & 1.0 & 1.0 & 0.6 & North \\
\hline \multirow[t]{4}{*}{ T6001 } & C611 & 403 & 12.4 & 4.7 & 1.4 & 1.1 & North \\
\hline & C612 & 359 & 14.1 & 3.3 & 1.3 & 1.2 & Central \\
\hline & C613 & 11 & 7.2 & 0.5 & 0.5 & 0.2 & South \\
\hline & C614 & 8 & 17.6 & 1.0 & 0.5 & 0.2 & South \\
\hline \multirow[t]{4}{*}{ T7000 } & C702 & 904 & 14.3 & 3.2 & 1.3 & 1.1 & Central \\
\hline & C701 & 765 & 10.7 & 4.1 & 1.3 & 1.1 & North \\
\hline & C704 & 30 & 16.5 & 1.5 & 0.6 & 0.3 & South \\
\hline & C703 & 33 & 7.0 & 0.4 & 0.5 & 0.2 & South \\
\hline \multirow[t]{2}{*}{ T7001 } & C712 & 430 & 15.0 & 3.7 & 1.4 & 1.1 & Central \\
\hline & C711 & 272 & 12.0 & 4.9 & 1.1 & 0.9 & North \\
\hline
\end{tabular}




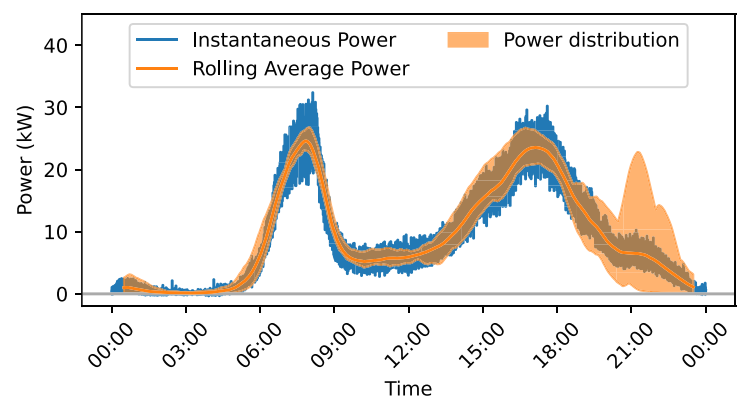

(a)

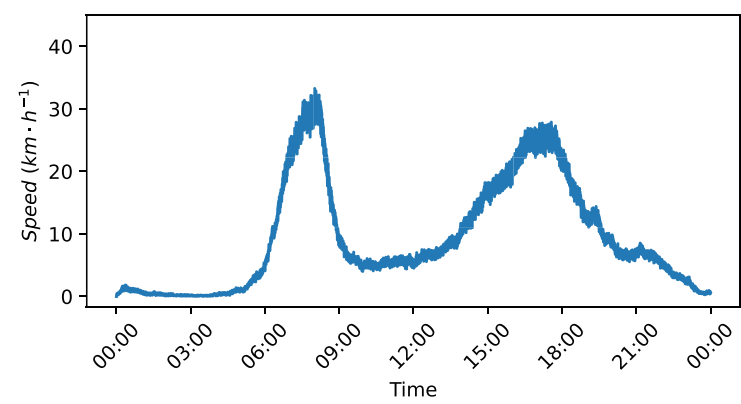

(b)

Fig. 3. Plots of (a) the mean power-usage profile and (b) the mean speed profile of the fleet of simulated eMBTs.

opportunities for charging these vehicles from solar PV systems. To discover the eMBTs' opportunities and requirements if they are to charge during stationary periods, we did a 24-h analysis of the start times and the durations of stop events. The analysis shows what the average charger capacity should be if a vehicle is charged using only power from the local electrical network. We applied a minimum stop duration of $20 \mathrm{~min}$ and a maximum stop duration of $8 \mathrm{~h}$ to ensure that only valid operational stops would be identified and that drop or pick up and go events were not included as charging opportunities. We chose the maximum of $8 \mathrm{~h}$ because a taxi in normal service would not stop for longer than that on a week day.

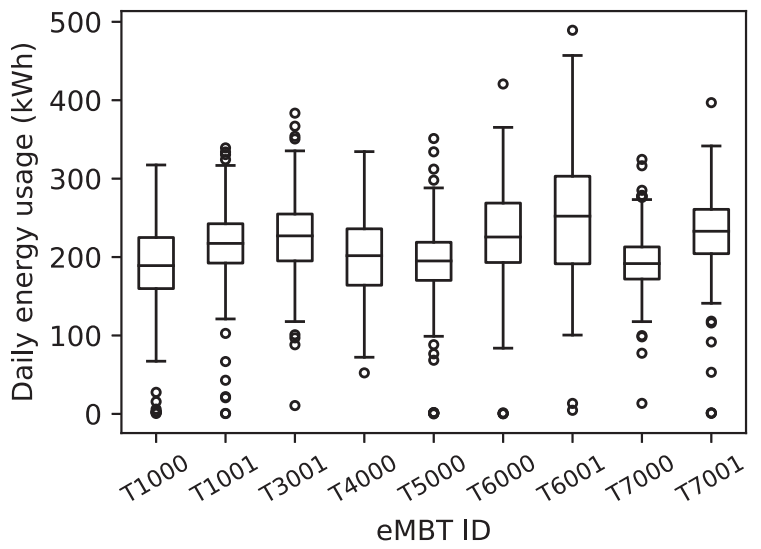

(a) Energy used per eMBT.

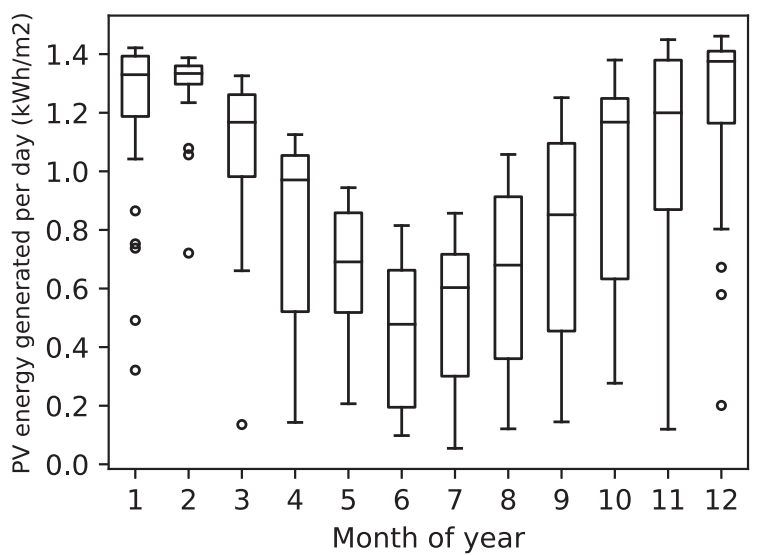

(c) PV generation per $m^{2}$ per month.

\section{Charging from the grid}

Fig. 4b shows the distribution of stop events across days, with the minimum and maximum stop duration thresholds applied. The figure shows that the MBTs' stop duration times vary considerably, with the median duration per day ranging from a minimum of $7.7 \mathrm{~h}$ for taxi T3001 to a maximum of $10.7 \mathrm{~h}$ for taxi T6000.

To calculate the charger capacity we used a relatively high energy demand and a relatively short charging time for a relatively demanding situation to obtain a conservative estimate of the charger capacity. We used the averages of the $75^{\text {th }}$ percentile of the energy usage (Fig. 4a) and the 25th percentile of the 24-h stop duration times (Fig. 4b) as

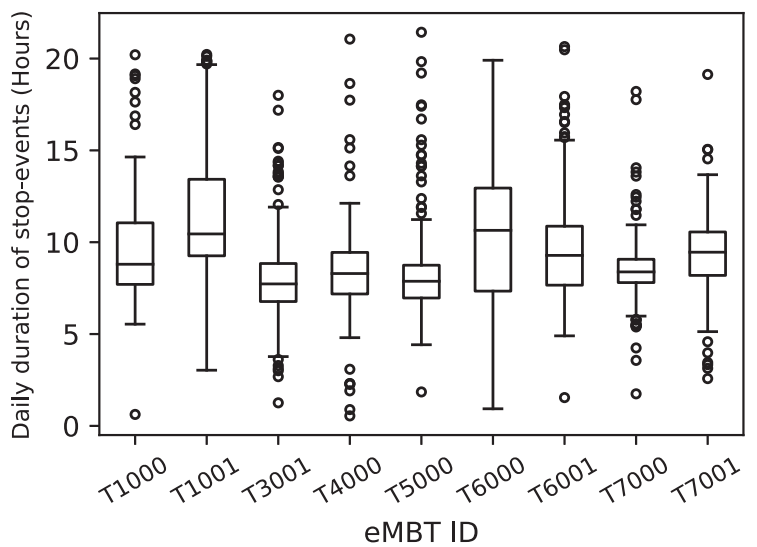

(b) Durations of stop events per eMBT.

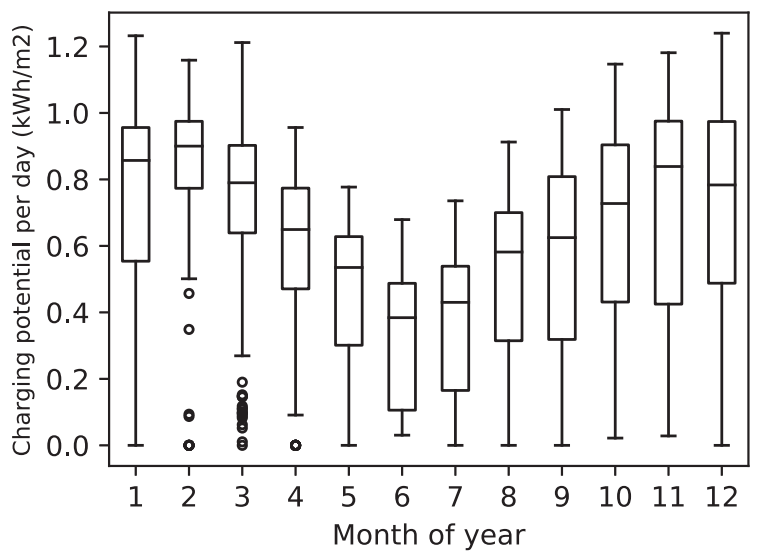

(d) PV charging potential per eMBT per $m^{2}$ per month.

Fig. 4. Summary of mobility, energy requirements, and charging potentials. 
$247 \mathrm{kWh}$ and $7.65 \mathrm{~h}$ respectively to calculate a charger capacity of 32.3 $\mathrm{kW}$. This assumes a constant charging profile and charging only from the local electrical grid.

\section{Charging from solar PV}

We evaluated the potential for charging the eMBTs from solar PV, both to reduce the load on the electrical grid and to reduce the size of the battery installed in the eMBT. The energy generated per surface area is shown in Fig. 4c for each month of the year, representing an upper bound of charging potential during stationary periods.

The aggregate charging potential per square metre of solar panel, for the fleet, is shown in Fig. 4d, indicating that a large amount of the generated energy could be used during stops. The disaggregated distribution of charging potential for each taxi, per square metre of solar panel, is shown in Fig. 5. The variation of charging potential between taxis is low, indicating that the taxis follow similar patterns during the daylight hours, and that they would require similar charging infrastructure. Assuming that the PV installations were sized to exploit the median stop potential per taxi, the mean potential would be $0.68 \mathrm{kWh} / \mathrm{m}^{2}$ and would vary from a minimum of $0.38 \mathrm{kWh} / \mathrm{m}^{2}$ to a maximum of $0.90 \mathrm{kWh} / \mathrm{m}^{2}$ during the year. The results show that a solar installation of approximately $320 \mathrm{~m}^{2}$ (equivalent to the total area of half a tennis court) would be required per taxi to ensure that the taxi's daily energy requirements are met by solar supply at least $50 \%$ of the time.
Given the estimated 285,000 taxis in South Africa, our analysis indicates that to charge all the minibus taxis from the national grid will require $9.72 \%$ (61.27GWh) of the current daily national energy generation. The average taxi would be able to directly utilise between $57 \%$ and $80 \%$ of installed PV generation capacity during normal stops.

\section{Conclusion}

This paper focuses on paratransit, a common feature in sub-Saharan Africa, which transports more than $70 \%$ of the region's commuters. One urgent outcome of the United Nations' Sustainable Development Goals is to decarbonise paratransit in the region. However, due to the sector's unstructured, unregulated and demand-driven nature, the lack of data on the mobility of minibus taxis poses a substantial challenge against these efforts.

We therefore formulated a structured approach for evaluating various metrics which can help to evaluate the feasibility and the design requirements of electric paratransit systems. The approach used easilyobtainable GPS tracking data and a traffic simulator to evaluate the electrical demand requirements of these vehicles, as well as the proportion of the demand that can be met by renewable energy. For the first time, using this method, an estimate could be given of the energy requirements of a hypothetical electrical paratransit system in SSA.

Paratransit mobility was characterised using GPS tracking data. These characteristics revealed that the mean distance travelled per

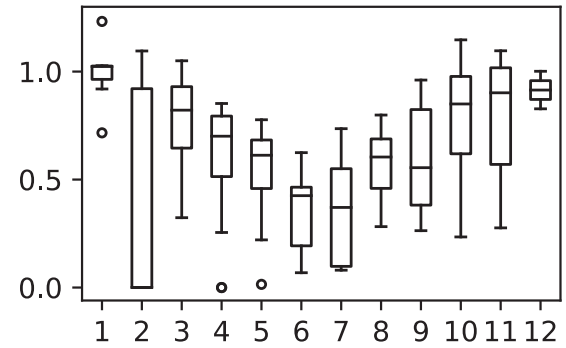

(a) T1000

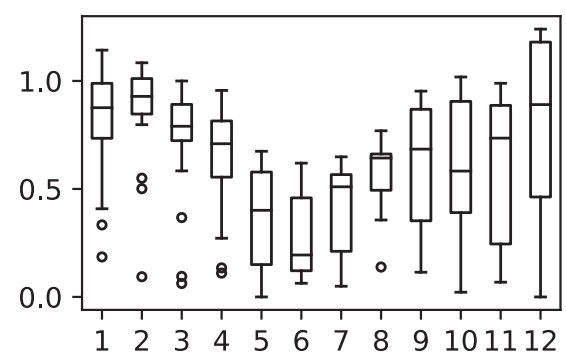

(d) $\mathrm{T} 4000$

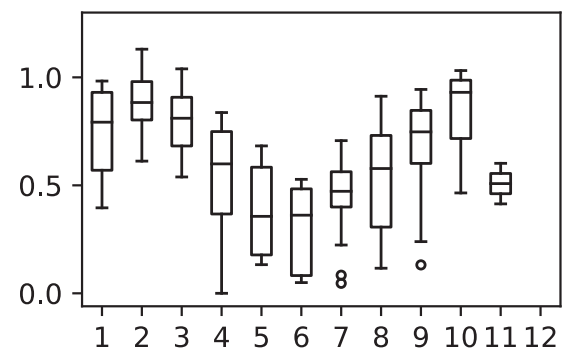

(g) T6001

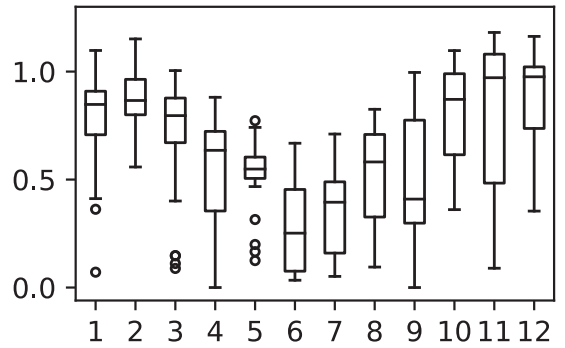

(b) T1001

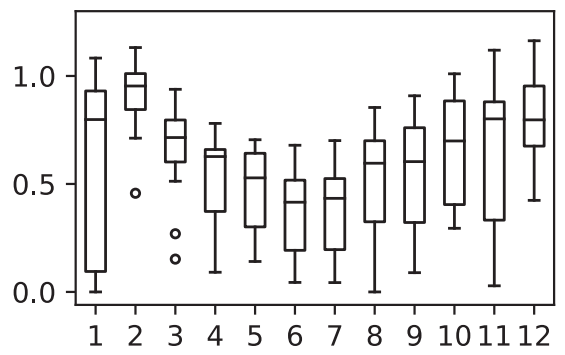

(e) T5000

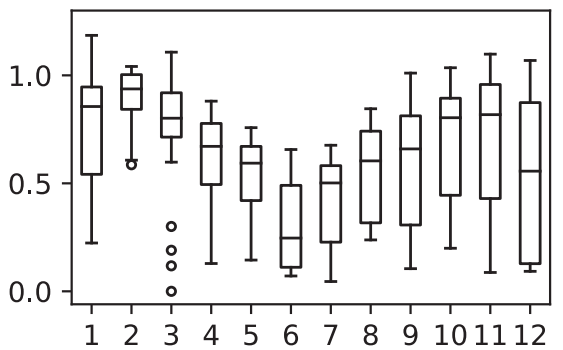

(h) T7000

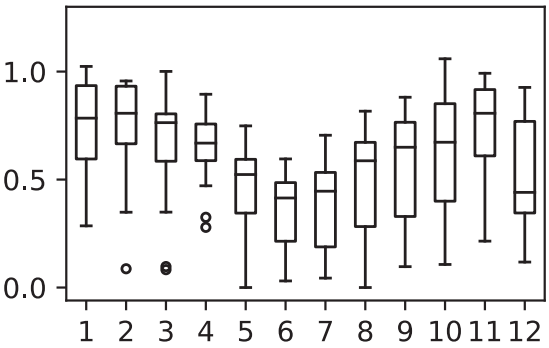

(c) T3001

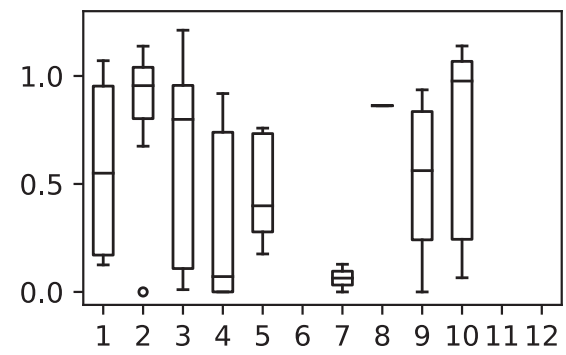

(f) T6000

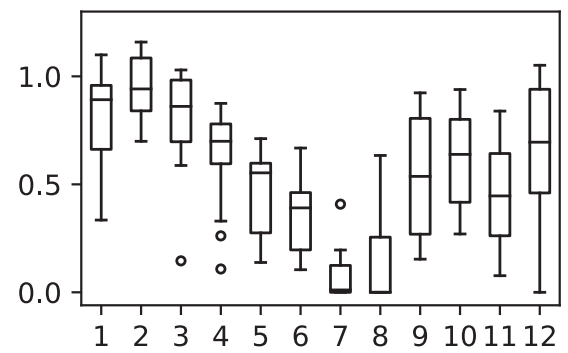

(i) T7001

Fig. 5. Disaggregated charging potential (in $\mathrm{kWh}^{2}$ ) per eMBT for each month of the year. 
taxi was $228 \mathrm{~km} /$ day. For each of the nine taxis, the median daily stop duration was calculated and was found to range from $7.7 \mathrm{~h}$ to $10.6 \mathrm{~h}$. This indicated that the energy demand would be quite high, and the time for charging would be quite low.

From the mobility characteristics, we found that a minibus-taxi would use approximately $215 \mathrm{kWh}$ to satisfy its daily mobility requirements. We found that taxis which were stopped for shorter periods, and hence had less time for charging, were also the ones that needed more energy because they were more mobile. Nonetheless, a charger of around $32 \mathrm{~kW}$ would be required. This meant that the total fleet of South Africa's minibus taxis would use around $10 \%$ of the daily national energy generation. This may not seem like a lot, but it would cover approximately $70 \%$ of the country's commuter trips, while incentivising investment into renewable energy infrastructure.

The sustainability of future paratransit needs to be coupled with a transition to renewable energy. Stellenbosch, like most other cities in SSA is privileged to have abundant sunshine. Therefore, photovoltaics was conceived as a potentially feasible renewable energy generator that can support electric paratransit. We found that a PV installation of $320 \mathrm{~m}^{2}$ (half the size of a tennis court) could satisfy the energy requirements of the average taxi $50 \%$ of the time. This took into account the daily solar irradiation profile and the times and durations that the taxi made its stops. Developing countries outside of Africa may not have such abundant sunshine, but the methodology uses software which includes models of other renewable energy generators.

Although these results are specific to a scenario in South Africa, the major contribution of this paper is the novel procedure for evaluating the impacts and opportunities of electric-vehicle roll-outs. The software is contributed, and can be easily modified to suit the context of other developing countries. For example, to evaluate the impact of electrification of India's auto rickshaws, the EV model parameters can be modified accordingly, and the PV simulation can be modified to include local weather conditions. The authors call for future work to be done to evaluate the energy requirements in other developing countries. The results of the program can be used not only by researchers, but also by gridoperators, traffic planners, and private-entities to obtain the financial, environmental, electrical, and mobility impacts of electric-vehicle rollouts of varying scales.

\section{Declaration of competing interest}

The authors declare that they have no known competing financial interests or personal relationships that could have appeared to influence the work reported in this paper.

\section{Acknowledgements}

The authords acknowledge MiX Telematics for the data, and MTN South Africa (through the MTN Mobile Intelligence Lab), and Eskom (through the Tertiary Education Support Programme) for sponsoring this research. We also thank the taxi owners and drivers for their participation.

\section{References}

Agbiboa, D. E. (2016). "No condition is permanent": Informal transport workers and labour precarity in Africa's Largest City. International Journal of Urban and Regional Research, 40, 936-957. https://doi.org/10.1111/1468-2427.12440.

Akumu, J. (2014). Improving air quality in African cities. Nairobi: UN Environment.

Amegah, A. K., \& Agyei-Mensah, S. (2017). Urban air pollution in Sub-Saharan Africa: Time for action. Environmental Pollution, 220, 738-743. https://doi.org/10.1016/j. envpol.2016.09.042.

Askari, S., Peiravian, F., Tilahun, N., \& Yousefi Baseri, M. (2021). Determinants of users' perceived taxi service quality in the context of a developing country. Transportation Letters, 13, 125-137. https://doi.org/10.1080/19427867.2020.1714844.

Behrens, R., McCormick, D., \& Mfinanga, D. (2015). Paratransit in African cities: Operations, regulation and reform (1 ed.). London: Routledge. https://doi.org/10.4324/ 9781315849515.
Behrens, R., McCormick, D., Orero, R., \& Ommeh, M. (2017). Improving paratransit service: Lessons from inter-city matatu cooperatives in Kenya. Transport Policy, 53 79-88. https://doi.org/10.1016/j.tranpol.2016.09.003.

Black, A., Barnes, J., Makundi, B., \& Ritter, T. (2018). Electric two-wheelers in Africa? Markets, production and policy Conference on Green Transformation and Competitive Advantage Evidence from developing countries.

Blair, N., Dobos, A. P., Freeman, J., Neises, T., Wagner, M., Ferguson, T., Gilman, P., \& Janzou, S. (2014). System advisor model, SAM 2014.1.14: General description. https://www.osti. gov/biblio/1126294. https://doi.org/10.2172/1126294.

Booysen, M. J., Abraham, C. J., Rix, A. J., \& Ndibatya, I.Booyset et al.. (2021). Walking on sunshine: Pairing electric vehicles with solar energy for sustainable informal public transport in sub-Saharan Africa. engrXiv (preprint). https://doi.org/10.31224/osf.io/ 7a6k2 In preparation.

Booysen, M. J., Andersen, S. J., \& Zeeman, A. S. (2013). Informal public transport in SubSaharan Africa as a vessel for novel Intelligent Transport Systems. 16th International IEEE Conference on Intelligent Transportation Systems (ITSC 2013) (pp. 767-772). https://doi.org/10.1109/ITSC.2013.6728324.

Buresh, K.M., Apperley, M.D., Booysen, M.J., 2020. Three shades of green: Perspectives on at-work charging of electric vehicles using photovoltaic carports. Energy for Sustainable Development 57, 132-140. doi: https://doi.org/10.1016/j.esd.2020.05.007.

Cervero, R., \& Golub, A. (2007). Informal transport: A global perspective. Transport Policy, 14, 445-457. https://doi.org/10.1016/J.TRANPOL.2007.04.011.

Collett, K. A., \& Hirmer, S. A. (2021). Data needed to decarbonize paratransit in SubSaharan Africa. Nature Sustainability. https://doi.org/10.1038/s41893-021-00721-7.

Dalal, S., Beunza, J. J., Volmink, J., Adebamowo, C., Bajunirwe, F., Njelekela, M., ... Holmes, M. D. (2011). Non-communicable diseases in sub-Saharan Africa: what we know now. International Journal of Epidemiology, 40, 885-901. https://doi.org/10.1093/ije/ dyr050.

Damiani, M. L., Issa, H., \& Cagnacci, F. (2014). Extracting stay regions with uncertain boundaries from GPS trajectories: A case study in animal ecology. Proceedings of the 22nd ACM SIGSPATIAL international conference on advances in geographic information systems (pp. 253-262). New York, NY, USA: Association for Computing Machinery. https://doi.org/10.1145/2666310.2666417.

Diaz Olvera, L., Plat, D., \& Pochet, P. (2019). Looking for the obvious: Motorcycle taxi services in Sub-Saharan African cities. Journal of Transport Geography, 102476. https:// doi.org/10.1016/J.JTRANGEO.2019.102476.

Dorothy, M., Herrie, S., \& David, M. (2016). The nature of paratransit operations. In B. Roger, M. Dorothy, \& M. David (Eds.), Paratransit in African cities: Operations, regulation and reform (1 ed.). Chapter 3. (pp. 59-78). New York: Routledge.

Du, J., Ouyang, M., \& Chen, J. (2017). Prospects for Chinese electric vehicle technologies in 2016-2020: Ambition and rationality. Energy, 120, 584-596. https://doi.org/10.1016/ j.energy.2016.11.114.

Ebot Eno Akpa, N. A., Booysen, M. J., \& Sinclair, M. (2016). A comparative evaluation of the impact of average speed enforcement (ASE) on passenger and minibus taxi vehicle drivers on the R61 in South Africa. Journal of the South African Institution of Civil Engineering, 58, 2-10. https://doi.org/10.17159/2309-8775/2016/v58n4a1.

Ehebrecht, D., Heinrichs, D., \& Lenz, B. (2018). Motorcycle-taxis in sub-Saharan Africa: Current knowledge, implications for the debate on "informal" transport and research needs. Journal of Transport Geography, 69, 242-256. https://doi.org/10.1016/j. jtrangeo.2018.05.006

Evans, J., O'Brien, J., \& Ch Ng, B. (2018). Towards a geography of informal transport: Mobility, infrastructure and urban sustainability from the back of a motorbike. Transactions of the Institute of British Geographers, 43, 674-688. https://doi.org/10. $1111 / \operatorname{tran} .12239$

Fridlund, J., \& Wilen, O. (2020). Parameter guidelines for electric vehicle route planning.

Galuszka, J., Martin, E., Nkurunziza, A., Achieng' Oginga, J., Senyagwa, J., Teko, E., \& Lah, O. (2021). East Africa's policy and stakeholder integration of informal operators in electric mobility transitions-Kigali, Nairobi, Kisumu and Dar es Salaam. Sustainability, 13. https://doi.org/10.3390/su13041703.

Goodfellow, T. (2017). Double capture' and de-democratisation: Interest group politics and Uganda's 'Transport Mafia. The Journal of Development Studies, 53, 1568-1583. https://doi.org/10.1080/00220388.2016.1214722.

Hecht, D. (2007). Invisible Governance: The Art of African Micropolitics. New Yoork: Autonomedia.

Jadhav, A. S., Chembe, D. K., Strauss, J. M., \& Van Niekerk, J. L. (2017). Status of solar technology implementation in the Southern African Developing Community (SADC) region. Renewable and Sustainable Energy Reviews, 73, 622-631. https://doi.org/10. 1016/j.rser.2017.01.113.

Jennings, G., \& Behrens, R. (2017). The case for investing in Paratransit: Strategies for regulation and reform

KCCA (2016). Multimodal urban transport master plan for Greater Kampala Metropolitan Area. Technical Report. Kampala: Kampala Capital City Authority (KCCA).

Krüger, F., Titz, A., Arndt, R., Groß, F., Mehrbach, F., Pajung, V., Suda, L., Wadenstorfer, M., \& Wimmer, L. (2021). The Bus Rapid Transit (BRT) in Dar es Salaam: A pilot study on critical infrastructure, sustainable urban development and livelihoods. Sustainability, 13. https://doi.org/10.3390/su13031058.

Kumar, A. M. (2011). Understanding the emerging role of motorcycles in African cities: A political economy perspective. Technical report 13. Washington, DC: Washington, DC: World Bank.

Kumar, Ajay Mahaputra, Foster, Vivien, \& Barrett, Fanny (2008). Stuck in traffic: Urban tr. ansport in Africa. Technical Report. Washington, DC: World Bankhttp://siteresources. worldbank.org/EXTAFRSUBSAHTRA/Resources/Stuck-in-Traffic.pdf.

Kurczveil, T., López, P.Á., \& Schnieder, E. (2014). Implementation of an energy model and a charging infrastructure in SUMO. In M. Behrisch, D. Krajzewicz, \& M. Weber (Eds.), Simulation of Urban Mobility (pp. 33-43). Berlin Heidelberg, Berlin, Heidelberg: Springer. 
Lah, O. (2017). Decarbonizing the transportation sector: policy options, synergies, and institutions to deliver on a low-carbon stabilization pathway. WIREs Energy and Environment, 6, Article e257. https://doi.org/10.1002/wene.257.

Le Roux, W. G. (2016). Optimum tilt and azimuth angles for fixed solar collectors in South Africa using measured data. Renewable Energy, 96, 603-612. https://doi.org/10.1016/ j.renene.2016.05.003

Le, T. P. L., \& Trinh, T. A. (2016). Encouraging public transport use to reduce traffic congestion and air pollutant: A case study of Ho Chi Minh City, Vietnam. Procedia Engineering, 142, 236-243. https://doi.org/10.1016/j.proeng.2016.02.037.

Lewis, R. (2020). Algorithms for finding shortest paths in networks with vertex transfer penalties. Algorithms, 13. https://doi.org/10.3390/a13110269.

Li, Y., Davis, C., Lukszo, Z., \& Weijnen, M. (2016). Electric vehicle charging in China's power system: Energy, economic and environmental trade-offs and policy implications. Applied Energy, 173, 535-554. https://doi.org/10.1016/j.apenergy.2016.04.040.

Liu, Q., Deng, M., Shi, Y., \& Wang, J. (2012). A density-based spatial clustering algorithm considering both spatial proximity and attribute similarity. Computers $\mathcal{E}$ Geosciences, 46, 296-309. https://doi.org/10.1016/j.cageo.2011.12.017.

Lopez, P. A., Behrisch, M., Bieker-Walz, L., Erdmann, J., Flötteröd, Y. P., Hilbrich, R., ... Wießner, E. (2018). Microscopic traffic simulation using SUMO. . 2019 IEEE Intelligent Transportation Systems Conference (ITSC) (pp. 2575-2582). IEEEhttps://elib.dlr.de/ $127994 /$.

Lozano Gracia, N., Bainomugisha, E., Soppelsa, M. E., \& Okure, D. (2021). . Characterization of ambient air quality in selected urban areas in Uganda: A low-cost approach. Technical report 9512. https://ideas.repec.org/p/wbk/wbrwps/9512.html.

Lucas, K., Jennings, G., Zuidgeest, M., Behrens, R., Venter, C., Mitullah, W., \& Thornton, B. (2019). Transport social exclusion in five African cities. Technical report. International network for transport and accessibility in low income communities. Leeds,UK. http:// www.vref.se/download/18.45182a5f16a84e95fac8b2b5/1561370471910/Transport.

Mutiso, W., \& Behrens, R. (2011). 'Boda Boda' bicycle taxis and their role in urban transport systems: case studies of Kisumu and Nakura, Kenya. 30th Annual Southern African Transport conference 11-14 July 2011 "Africa on the Move", CSIR International Convention Centre, Pretoria, South Africa (pp. 430-444). http://hdl.handle.net/2263/ 17308.

Ndibatya, I., \& Booysen, M. J. (2020). Minibus taxis in Kampala's paratransit system: Operations, economics and efficiency. Journal of Transport Geography, 88. https://doi.org/ 10.1016/j.jtrangeo.2020.102853.

Ndibatya, I., \& Booysen, M. J. (2021). Characterizing the movement patterns of minibus taxis in Kampala's paratransit system. Journal of Transport Geography, 92, 103001. https://doi.org/10.1016/j.jtrangeo.2021.103001.

Ndibatya, I., Booysen, M. J., \& Quinn, J. (2014). An adaptive transportation prediction model for the informal public transport sector in Africa. 17th international IEEE conference on Intelligent Transportation Systems (ITSC) (pp. 2572-2577).

Neumann, A., \& Joubert, J. W. (2016). The "Minibus" contribution. In Andreas Horni, Kai Nagel, \& Kay W. Axhausen (Eds.), The multi-agent transport simulation MATSim. London: Ubiquity Press. https://doi.org/10.5334/baw.17.

Odhiambo, E., Kipkoech, D., Hegazy, A., Hegazy, Mohamed, Manuel, Mikhail, Schalekamp, Herrie, \& Klopp, Jacquiline, MEdna et al.. (2021). The potential for minibus electrification in three African cities: Cairo, Nairobi, and Cape Town. Volvo Research and Educational Foundations. https://doi.org/10.13140/RG.2.2.26552.26882.

OpenStreetMap contributors (2017). Planet dump. https://planet.osm.orghttps://www. openstreetmap.org.

Osei, L. K., Ghaffarpasand, O., \& Pope, F. D. (2021). Real-world contribution of electrification and replacement scenarios to the fleet emissions in West Midland Boroughs, UK. Atmosphere, 12. https://doi.org/10.3390/atmos12030332.

Pedregosa, F., Varoquaux, G., Gramfort, A., Michel, V., Thirion, B., Grisel, O., Blondel, M., Prettenhofer, P., Weiss, R., Dubourg, V., Vanderplas, J., Passos, A., Cournapeau, D., Brucher, M., Perrot, M., \& Duchesnay, E. (2011). Scikit-learn: Machine learning in python. Journal of Machine Learning Research, 12, 2825-2830.

Pojani, D., \& Stead, D. (2017). The urban transport crisis in emerging economies: An introduction. In D. Pojani, \& D. Stead (Eds.), The urban transport crisis in emerging economies (pp. 1-10). Cham: Springer International Publishing. https://doi.org/10.1007/ 978-3-319-43851-1_1.

Pojani, D., \& Stead, D. (2018). Policy design for sustainable urban transport in the global south. Policy Design and Practice, 1, 90-102. https://doi.org/10.1080/25741292.2018. 1454291.
Quirós-Tortós, J., Espinosa, A. N., Ochoa, L. F., \& Butler, T. (2018). Statistical representation of EV charging: Real data analysis and applications. 2018 Power Systems Computation Conference (PSCC) (pp. 1-7). https://doi.org/10.23919/PSCC.2018.8442988.

Rajé, F., Tight, M., \& Pope, F. D. (2018). Traffic pollution: A search for solutions for a city like Nairobi. Cities, 82, 100-107. https://doi.org/10.1016/j.cities.2018.05.008.

Renjith, S., Sreekumar, A., \& Jathavedan, M. (2020). Performance evaluation of clustering algorithms for varying cardinality and dimensionality of data sets. Materials Today: Proceedings, 27, 627-633. https://doi.org/10.1016/j.matpr.2020.01.110.

Sawadogo, W., Reboita, M. S., Faye, A., da Rocha, R. P., Odoulami, R. C., Olusegun, C. F., Adeniyi, M. O., Abiodun, B. J., Sylla, M. B., Diallo, I., Coppola, E., \& Giorgi, F. (2020). Current and future potential of solar and wind energy over Africa using the RegCM4 CORDEX-CORE ensemble. Climate Dynamics. https://doi.org/10.1007/s00382-02005377-1.

Schücking, M., Jochem, P., Fichtner, W., Wollersheim, O., \& Stella, K. (2017). Charging strategies for economic operations of electric vehicles in commercial applications. Transportation Research Part D: Transport and Environment, 51, 173-189. https://doi. org/10.1016/j.trd.2016.11.032.

Sengupta, M., Xie, Y., Lopez, A., Habte, A., Maclaurin, G., \& Shelby, J. (2018). The Nationa Solar Radiation Data Base (NSRDB). Renewable and sustainable energy reviews. 89. ( $\mathrm{pp}$ 51-60). https://doi.org/10.1016/j.rser.2018.03.003.

Shams, A., \& Zlatkovic, M. (2020). Effects of capacity and transit improvements on traffic and transit operations. Transportation Planning and Technology, 43, 602-619. https:// doi.org/10.1080/03081060.2020.1780710.

Sietchiping, R., Permezel, M. J., \& Ngomsi, C. (2012). Transport and mobility in sub-Saharan African cities: an overview of practices, lessons and options for improvements. Cities, 29, 183-189. https://doi.org/10.1016/j.cities.2011.11.005.

Sims, R., Schaeffer, R., Creutzig, F., Cruz-Núñez, X., D’Agosto, M., Dimitriu, D., ... Tiwari, G. (2014). Transport. In O. Edenhofer, R. Pichs-Madruga, Y. Sokona, E. Farahani, S. Kadner, K. Seyboth, \& J. Minx (Eds.), Climate change 2014: Mitigation of climate change. Contribution of working group III to the fifth assessment report of the intergovernmental panel on climate change. Chapter 8. (pp. 603). Cambridge, United Kingdom and New York, NY, USA: Cambridge University Press.

Singh, A., Avis, W. R., \& Pope, F. D. (2020). Visibility as a proxy for air quality in East Africa Environmental Research Letters, 15, 84002. https://doi.org/10.1088/1748-9326/ ab8b12.

Soares, P. M. M., Brito, M. C., \& Careto, J. A. M. (2019). Persistence of the high solar potential in Africa in a changing climate. Environmental Research Letters, 14, 124036. https://doi.org/10.1088/1748-9326/ab51a1.

United Nations, Department of Economic and Social Affairs, Population Division (2019). World population prospects 2019, custom data acquired via website. https://popula tion.un.org/wpp/DataQuery [Online; accessed 10. Aug. 2021].

Venter, C., Jennings, G., Hidalgo, D., \& Pineda, A. F. V. (2018). The equity impacts of bus rapid transit: A review of the evidence and implications for sustainable transport. International Journal of Sustainable Transportation, 12, 140-152. https://doi.org/10. 1080/15568318.2017.1340528.

Venter, C., Mahendra, A., \& Hidalgo, D. (2019). From mobility to access for all: Expanding urban transportation choices in the global south. World Resources Institute: Technical Report.

Weiss, M., Cloos, K. C., \& Helmers, E. (2020). Energy efficiency trade-offs in small to large electric vehicles. Environmental Sciences Europe, 32, 46. https://doi.org/10.1186/ s12302-020-00307-8.

World Health Organization, et al. (2018). Indicator 3.9.1: Mortality rate attributed to household and ambient air pollution (per 100000 population). https://www.who. int/data/gho/data/indicators/indicator-details/GHO/ambient-and-household-airpollution-attributable-death-rate-(per-100-000-population) [Online; accessed 10. Aug. 2021].

Zheng, Y., Zhang, L., Xie, X., \& Ma, W. Y. (2009). Mining interesting locations and travel sequences from GPS trajectories. Proceedings of the 18th International Conference on World Wide Web, Association for Computing Machinery, New York, NY, USA (pp. 791-800). https://doi.org/10.1145/1526709.1526816.

Zinkernagel, R., Evans, J., \& Neij, L. (2018). Applying the SDGs to cities: Business as usual or a new dawn? Sustainability, 10. https://doi.org/10.3390/su10093201. 